\title{
Treatment Outcomes of Pediatric Nephrotic Syndrome Patients Treated in Ayder Comprehensive Specialized and Mekelle General Hospitals, Ethiopia
}

\author{
Yainu Welegerima' \\ Mamo Feyissa $\mathbb{( D}^{2}$ \\ Teshome Nedi $\mathbb{I}^{2}$ \\ 'Department of Pharmacy, College of \\ Health Sciences, Mekelle University, \\ Mekelle, Tigray, Ethiopia; ${ }^{2}$ Department of \\ Pharmacology and Clinical Pharmacy, \\ School of Pharmacy, College of Health \\ Sciences, Addis Ababa University, Addis \\ Ababa, Ethiopia
}

Background: Nephrotic syndrome is a common glomerular disease in children with a relapsing course that leads to complications and steroid-related toxicities. In Ethiopia, data on the outcomes of steroid therapy in pediatric nephrotic syndrome patients are limited. Objective: The aim of the study was to assess the treatment outcomes of pediatric nephrotic syndrome patients in Ayder Specialized Comprehensive and Mekelle General Hospitals.

Methods: A retrospective study was conducted among children treated for nephrotic syndrome from 2010 to 2017 in Ayder Comprehensive Specialized and Mekelle General Hospitals. Univariate and multivariate logic regression analyses were performed to identify determinants of treatment outcome with a p-value $<0.05$ considered statistically significant. Results: A total of 159 pediatric patients treated for nephrotic syndrome in both hospitals were included in this study. The mean age of participants at the initial diagnosis was $5.21 \pm$ 2.66 years. Most of the patients 150 (94.3\%) achieved remission within 4 weeks of steroid therapy. Among initial responders, the majority of the patients 117 (78\%) encountered relapses of which $65(40.9 \%)$ were developed frequent relapse/steroid-dependent nephrotic syndrome. Also, the majority of patients 102 (64.5\%) encountered steroid-related toxicities. The predictors of frequent relapse/steroid-dependent nephrotic syndrome were age of $\leq 6$ years $(A O R=3.16 ; p=0.00)$, hematuria $(A O R=6.74 ; p=0.00)$, infection $(A O R=3.28 ; p=0.01)$, acute renal failure $(A O R=6.09 ; \mathrm{p}=0.01)$, serum albumin below $1.5 \mathrm{~g} / \mathrm{dl}(8.38, \mathrm{p}=0.01)$ and lack of remission within 2 weeks ( $\mathrm{AOR}=3.69 ; \mathrm{p}=0.00)$.

Conclusion: Most of the pediatric NS patients treated in ACSH and MGH have achieved remission with initial to steroid therapy. However, there was a higher relapse rate and steroidrelated toxicities among pediatric NS patients who achieved remission. Early age at diagnosis, hematuria, reduced GFR, infection, and remission time were the independent predictors of the frequent relapsing/steroid-dependent nephrotic disease course.

Keywords: nephrotic syndrome, steroid therapy, treatment outcome, steroid sensitive NS, relapses with steroid therapy

\section{Background}

Nephrotic syndrome (NS) is a common glomerular disease in children characterized by proteinuria ( $\geq 40 \mathrm{mg} / \mathrm{m}^{2} / \mathrm{hr}$ or urine protein/creatinine ratio $\geq 200 \mathrm{mg} / \mathrm{mmol}$ or $\geq 3$ + protein on urine dipstick), hypoalbuminemia $(<2.5 \mathrm{gm} / \mathrm{dl})$, generalized edema and hypercholesterolemia $(>200 \mathrm{mg} / \mathrm{dl}){ }^{1,2}$ It is one of the common childhood kidney diseases which affects up to 16 in 100,000 children. ${ }^{3,4}$ However, there is substantial variability in the incidence of NS with ethnic background and geographical 
location. ${ }^{5}$ A study in the United States indicated that there is a higher incidence of NS in African children. ${ }^{6}$

The majority of the pediatrics NS patients present with idiopathic minimal change nephrotic syndrome (MCNS), which has a favorable response to treatment. ${ }^{7}$ Over $80-90 \%$ of MCNS patients are steroid-sensitive and respond to standard prednisolone therapy with complete resolution of proteinuria. However, most patients tend to relapse, and around 50\% become frequent relapsing and/or steroid-dependent (FR/SD NS). Patients developing FR/ SD NS require prolonged treatment that leads to toxicity, systemic infections, and other complications. ${ }^{8-10}$ The common complications experienced with prolonged steroid treatment were cushingoid features, hypertension, hyperlipidemia, hyperglycemia, serious infections, growth retardation, stunted growth, osteopenia, and overall poor quality of life., ${ }^{9,11}$

African children have an increased likelihood of developing focal segmental glomerulosclerosis. ${ }^{6,12}$ This is the most challenging form of NS associated with severe and prolonged proteinuria, high risk of complications, and mortality. ${ }^{11,13}$ This form of NS is mostly resistant to corticosteroid therapy and other immunosuppressive treatment. ${ }^{14}$ Besides, steroid-resistant NS is reported in $16-27 \%$ of African children, ${ }^{6,15}$ which is about 2-4 times higher than rates in children of Asian and European descent. ${ }^{15}$

Corticosteroids remained the first-line standard treatment for NS to achieve complete remission. ${ }^{10}$ Despite the high rate of initial remission to corticosteroids therapy, relapses are common leading to increased morbidity and cost of treatment. ${ }^{7}$ There is a wide inter-individual variation in the clinical course, treatment response, and treatment side effects among pediatrics, which makes it difficult to predict the treatment outcome. ${ }^{10}$ Black children respond poorly to corticosteroid and other immunosuppressive treatment and have a higher mortality rate. ${ }^{14}$

Studies identified different factors to be associated with FR/SD NS, which is an indicator of poor treatment outcome. The presence of hematuria, time taken to respond during initial therapy, and duration of steroid therapy were associated with higher FR/SD NS. ${ }^{16,17}$ Also, time to first relapse and inadequate initial therapy were reported as predictors of developing FR/SD NS disease course. ${ }^{9}$ Patients with frequently relapsing nephrotic syndrome have treatment options that include extended dosing of glucocorticoids, cytotoxic agents, mycophenolate mofetil, or calcineurin inhibitors. ${ }^{1}$
In Ethiopia, there are limited studies on the treatment outcomes of pediatrics NS although it was the second most common cause of pediatric admissions due to renal disease according to a study in Tikur Anbessa Specialized Hospital. ${ }^{18}$ A study by Gebrehiwot et al has reported a $35.6 \%$ incidence of relapse with steroid treatment among pediatric NS patients. ${ }^{19}$ Although repeated hospitalizations, higher steroid side effects, and increased economic and social burdens occur with relapsing steroid therapy; there are no other interventions to spare steroid therapy in Ethiopia. As the disease burden and response to therapy varies by ethnicity and geographic location, it is vital to study the treatment outcome and associated factors in pediatric NS patients in Ethiopia. Therefore, this study is aimed to assess the treatment outcome of pediatric NS patients treated with steroid in Ayder Comprehensive Specialized and Mekelle General Hospitals in Tigray, Ethiopia.

\section{Methods \\ Study Area}

This study was conducted in Ayder Comprehensive Specialized Hospital (ACSH) and Mekelle General Hospital (MGH), both located in Mekelle city, Tigray State, Ethiopia,783 KM away from Addis Ababa, the capital city. ACSH serves about eight million populations in its catchment areas of the Tigray, Afar, and Southeastern parts of the Amhara Regional States. It is the largest teaching hospital in Tigray, with a total of 500 beds and several specialty outpatient clinics. On the other hand, MGH has 100 inpatient beds that provide services to patients coming to nearby areas including Afar Region. The diagnosis and management for nephrotic syndrome are provided at the pediatric department of both hospitals.

\section{Study Design}

This study was based on the retrospective review of the medical records of pediatric NS patients treated in both hospitals in the past 8 years (years 2010-2017).

\section{Source and Study Population}

All the pediatric patients admitted and treated in ACSH and MGH during the study period were the source population. The study population were all patients who have been treated for NS in the pediatric ward of ACSH and MGH. 


\section{Study Participants}

The study included all children (age $<18$ years) who have been diagnosed and treated for NS during the study period, and with the complete data on the medical record. The pediatric patients who met diagnostic criteria of NS; proteinuria $\left(\geq 40 \mathrm{mg} / \mathrm{m}^{2} / \mathrm{hr}\right.$ or urine protein/ creatinine ratio $\geq 200 \mathrm{mg} / \mathrm{mmol}$ or $\geq 3+$ protein on urine dipstick), hypoalbuminemia $(<2.5 \mathrm{gm} / \mathrm{dl})$, generalized edema and hypercholesterolemia $(>200 \mathrm{mg} / \mathrm{dl})$ and treated with steroid were included. The medical records with incomplete data (laking proteinurea, dosage of steroid and treatment outcomes) were excluded.

\section{Study Variables}

The dependent variable for this study was the treatment outcome of pediatric NS patients to steroid therapy. The treatment outcomes include achieving remission within 4 weeks of therapy, occurrence of relapse and side effects from steroid therapy. The independent variables include the demographic variables (age, sex); treatment, and disease-related variables such as duration of treatment, presence of complications, number of relapse/hospitalization, and length of hospital stay, time to the first relapse from remission, baseline clinical presentation, time to remission, duration of treatment, frequency of administration, and presence of baseline complications (hypertension, diabetes mellitus, thrombosis). Also, baseline laboratory findings like serum creatinine, triglyceride, total cholesterol were considered as independent variables.

\section{Data Collection Process}

The pilot-tested structured data abstraction form was used to collect relevant data from all medical records identified. The data abstraction form included the demographic characteristics (age and gender), clinical information, the number of drugs prescribed, the duration of therapy, and the treatment outcome. The medical records were identified by swotting the patient registration book and retrieving the chart using the medical record number for NS patients admitted from September 2010 to September 2017. Four data collectors were recruited among clinical pharmacists who are working in hospitals. The data collectors have been trained for 1 day on the objective of the study and how to properly use the data abstraction form to collect the required data from medical records. The data collection was conducted from July to
November 2019. The primary investigator daily checks the completeness and correctness of collected data to ensure its quality.

\section{Data Analysis and Interpretation}

The collected data were entered, cleaned, and analyzed using SPSS version 23. Simple descriptive statistics such as frequencies, proportions, and percentages were used to describe the demographic and clinical characteristics of participants. Univariate and multivariate logistic regression statistical tests were performed to identify the independent associations and predictors of treatment outcome. Variables that have $p$ values of $<0.25$ in Univariate analysis were taken to multivariable logistic regression analysis. At a 95\% confidence interval, $\mathrm{p}<0.05 \%$ was considered statistically significant in all tests.

\section{Ethical Considerations}

Ethical clearance to conduct this study was approved by the Ethical Review Committee (ERC) of the School of Pharmacy, College of Health Sciences, Addis Ababa University. The confidentiality of data collected was maintained by omitting patient identifiers from the questionnaire and maintaining filled data securely. As the retrospective study based on medical records, there was no direct contact with patients to secure informed consent. But permission to access and review the patient medical records was obtained from the hospital management of both hospitals before data collection. Also, the study was conducted following the standards of the Helsinki declaration.

\section{Operational Definitions}

Remission: Urine protein/creatinine ratio ( $\mathrm{UPCR}$ ) $<200 \mathrm{mg} / \mathrm{mmol}$ or $<1+$ of protein on urine dipstick for 3 consecutive days

Relapse: is defined as a reappearance of proteinuria; $3+$ or $4+$ on the dipstick for 3 consecutive days and can be either frequent or infrequent.

Infrequent relapse NS: one relapse in 6 months or less than 3 relapses in a year

Frequent relapse NS: two or more relapses in the initial 6 months or more than 4 relapses in a year.

Steroid-dependent nephrotic syndrome (SDNS): is a form of a nephrotic syndrome characterized by relapse following dose reduction or within two weeks steroid discontinuation.

Steroid resistance: failure to achieve remission within 8 weeks of initial steroid therapy. 


\section{Results}

\section{Sociodemographic and Clinical}

\section{Characteristics}

During the study period, a total of 165 pediatric patients treated for NS were identified of which 6 were excluded due to incomplete data on their medical records. Thus, this study included a total of 159 children (94 in ACSH and 65 in MGH) treated for NS. The majority of children were boys 104 (65.4\%), between the age of $4-8$ years $76(47.8 \%)$ mean age being $5.21 \pm$ 2.66 years, and have +3 proteinuria $124(78 \%)$ at initial diagnosis. Regarding the associated comorbidities, about half $76(47.8 \%)$ had infections, 25 (15.7\%) had reduced GFR, 68 (42.8\%) had hematuria, and 32 (20.1\%) patients were found with other comorbid diseases. Table 1 describes the demographic and clinical characteristics of NS pediatric patients at initial diagnosis.

The mean baseline serum triglyceride, total cholesterol, serum creatine, and albumin were 162.92 ( $\pm 44.79 \mathrm{SD})$, $252.75 \quad( \pm 57.05 \quad \mathrm{SD}), \quad 0.66 \quad( \pm 0.25 \mathrm{SD}), \quad$ and 2.03 $( \pm 0.46 \mathrm{SD})$, respectively. The length of hospital stay for the patients ranges from 5 to 35 days with an average of 13.37 days as shown in Table 2.

\section{The Outcome of NS Patients to Standard Course of Steroid Therapy}

Among the study participants, a total of 150 (94.3\%) NS pediatric patients achieved remission in 4 weeks of therapy and $9(5.7 \%)$ did not respond at all. More than half $80(53.3 \%)$ the remission occurred within 2 weeks of steroid therapy. However, only 33 (20.8\%) patients remained steroid-sensitive throughout the follow-up period. About three-fourths (117 [73.6\%]) of patients relapse after achieving remission; $52(32.7 \%)$ patients develop infrequent relapse and $65(40.9 \%)$ patients had FR/SD NS. Figure 1 shows the steroid treatment response among children treated for NS.

Besides remission, treatment-related adverse effects were identified. A total of 102 patients developed steroid-related adverse effects, which include increased blood glucose $29(18.2 \%)$, elevated blood pressure (BP) 28 (17.9\%), moon face 25 (15.7\%), dyspepsia 20 (12.6\%), glaucoma/conjunctivitis $4(2.5 \%)$ and psychosis $3(1.9 \%)$.
Table I Demographic and Clinical Characteristics of NS Patients in ACSH and Mekelle General Hospital $(n=159)$

\begin{tabular}{|c|c|c|}
\hline Characteristics & Frequency & Percent \\
\hline \multicolumn{3}{|l|}{ Gender } \\
\hline Male & 104 & 65.4 \\
\hline Female & 55 & 34.6 \\
\hline \multirow{2}{*}{\multicolumn{3}{|c|}{ Age at diagnosis (Mean \pm SD) $(5.21$}} \\
\hline & & \\
\hline I-4 years & 68 & 42.8 \\
\hline $4-8$ years & 76 & 47.8 \\
\hline $8-15$ years & 15 & 9.4 \\
\hline \multicolumn{3}{|l|}{ Urine protein } \\
\hline+3 & 124 & 78 \\
\hline+4 & 35 & 22 \\
\hline \multicolumn{3}{|l|}{ Hematuria } \\
\hline Yes & 68 & 42.8 \\
\hline No & 91 & 57.2 \\
\hline \multicolumn{3}{|l|}{ Duration of treatment } \\
\hline 12 weeks & $|3|$ & 82.4 \\
\hline 8 weeks & 28 & 17.6 \\
\hline \multicolumn{3}{|l|}{ Frequency of administration } \\
\hline Once-daily & 29 & 18.2 \\
\hline Twice-daily & 130 & 81.8 \\
\hline \multicolumn{3}{|l|}{ Comorbid diagnosis* } \\
\hline Present & 32 & 20.1 \\
\hline Absent & 127 & 79.9 \\
\hline \multicolumn{3}{|l|}{ Acute renal failure } \\
\hline Yes & 25 & 15.7 \\
\hline No & 134 & 84.3 \\
\hline \multicolumn{3}{|l|}{ Infection } \\
\hline Present & 79 & 49.7 \\
\hline Pneumonia & 32 & 40.5 \\
\hline Upper respiratory tract infections & 14 & 17.7 \\
\hline Meningitis & 10 & 12.6 \\
\hline Urinary tract infection & 7 & 8.9 \\
\hline Spontaneous bacterial infection & 5 & 6.3 \\
\hline Sepsis & 8 & 10.1 \\
\hline Osteomyelitis & 3 & 3.8 \\
\hline Absent & 80 & 50.3 \\
\hline
\end{tabular}

Note: *Include elevated BP, blood glucose, thrombosis. Abbreviation: SD, standard deviation.

\section{The Determinant Factors for Poor}

\section{Prognosis}

As described in Table 3, factors independently associated with steroid treatment outcome were age, presence of hematuria, infection, acute renal failure, time for initial remission, and low serum albumin. 
Table 2 Laboratory Findings of Pediatric NS Patients at Initia Presentation, $\mathrm{ACSH}$, and $\mathrm{MGH}$

\begin{tabular}{|l|l|l|l|}
\hline $\begin{array}{l}\text { Laboratory } \\
\text { Variables }\end{array}$ & Minimum & Maximum & Mean \pm SD \\
\hline $\begin{array}{l}\text { Random blood } \\
\text { glucose }\end{array}$ & 56 & 158 & $85.6101 \pm 16.96$ \\
\hline Total cholesterol & 138 & 472 & $252.7484 \pm 57.05$ \\
\hline Serum TG & 103 & 659 & $162.95 \pm 44.79$ \\
\hline Serum album & 1.20 & 3.20 & $2.0254 \pm 0.46$ \\
\hline Serum creatinine & 0.20 & 1.50 & $0.6597 \pm 0.25$ \\
\hline
\end{tabular}

Abbreviations: SD, standard deviation; LOS, length of stay; TG, triglyceride.

Based on the initial patient presentation at diagnosis, the odds of poor prognosis was higher among children with age of $\leq 6$ years $(\mathrm{AOR}=3.16 ; 95 \%$ CI: $1.23-8.16$, $\mathrm{p}=0.00)$, hematuria $(\mathrm{AOR}=6.74 ; 95 \% \mathrm{CI}: 2.53-17.96$, $\mathrm{p}=0.00)$, infection $(\mathrm{AOR}=3.28 ; 95 \%$ CI: 1.35-7.97, $\mathrm{p}=0.01$ ), acute renal failure (AOR=6.09; 95\% CI: $1.60-$ 23.10, $\mathrm{p}=0.01)$, serum albumin below $1.5 \mathrm{~g} / \mathrm{dl}(8.38, \mathrm{CI}$ $1.71-41.13, \mathrm{p}=0.01)$. The related factor that predict poor prognosis is achieving remission after 2 weeks of therapy ( $\mathrm{AOR}=3.69 ; 95 \%$ CI: $1.53-9.09, \mathrm{p}=0.00)$.

\section{Discussion}

This study has determined the treatment outcome of the pediatric nephrotic syndrome patients with steroids in two hospitals located in Tigray, Ethiopia. Accordingly, $94.3 \%$ of the participants achieved remission within 4 weeks of steroid therapy, among which $50.3 \%$ achieved remission within 2 weeks of treatment. This finding is similar to the $90-95 \%$ rate of response to steroid therapy in minimal change NS children. ${ }^{7,20,21}$ However, our finding is higher as compared to response rates of $57.7 \%$ in South Africa, ${ }^{22} 61 \%$ in Ethiopia, ${ }^{23} 63 \%$ in tropical Africa, ${ }^{12}$ and $74 \%$ in Nigeria $^{24}$ achieved within 4 weeks of treatment. Achieving remissions with steroid therapy in 8 weeks is predictive of $\mathrm{MCNS}^{3}$ suggesting most of our participants had MCNS. The possible reason for this variation could be the difference among the study participants, age at diagnosis, ethnicity, or presence of complication at diagnosis. For instance, the mean age of our study participants was 5.21 years whereas the mean ages of participants were 5.3 and 7.9 years in studies by Bakhiet et $\mathrm{al}^{22}$ and Asinobi et $\mathrm{al}^{12}$ respectively, and median age of 3 years in a study by Imbusi ea al. ${ }^{23}$

Despite a good response rate with initial steroid therapy, our study found $73.6 \%$ relapse among the initial responders. This relapse rate is consistent with reports of the relapse rates between $60 \%$ and $90 \%$ among initial responder pediatric NS patients. ${ }^{7,21}$ In contrast to our finding, a study by Gebrehiwot et al has reported a lower relapse rate of $35.6 \%$ with steroid treatment. ${ }^{19}$ However, the relapse rate in this study is lower than the $89.7 \%$ relapse rate reported in Sudan. ${ }^{25}$

Patients that encounter frequent relapses and/or steroid dependence indicate unfavorable features suggesting poor prognosis. ${ }^{1}$ Among our study participants, $40.9 \%$ of patients had FR/SD NS disease course. This is lower than the study findings of FR/SD NS disease course in

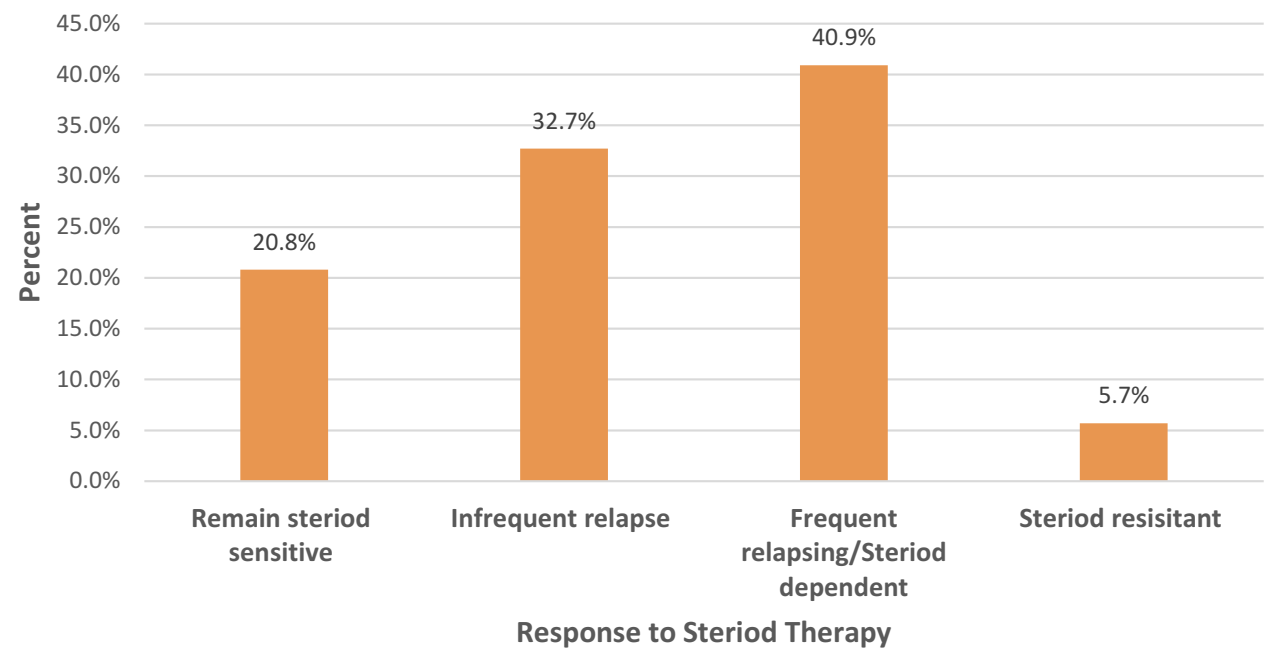

Figure I The treatment outcome of childhood NS patients to the standard course of steroid therapy in ACSH and Mekelle General Hospital. 
Table 3 Determinants for the Steroid Response in Pediatric Nephrotic Syndrome Patients in ACSH and Mekelle General Hospitals $(n=150)$

\begin{tabular}{|c|c|c|c|c|c|}
\hline \multirow[t]{2}{*}{ Variables } & \multicolumn{2}{|c|}{ Steroid Treatment Outcome } & \multirow{2}{*}{$\begin{array}{l}\text { Univariate Analysis } \\
\text { P-value* }\end{array}$} & \multicolumn{2}{|c|}{ Multivariate Logistic Regression } \\
\hline & SS/IR NS n (\%) & FR/SD NS n (\%) & & AOR $(95 \% \mathrm{Cl})$ & P-value* \\
\hline \multicolumn{6}{|l|}{ Gender } \\
\hline Male & $49(50.5)$ & $48(49.5)$ & 0.06 & $\mathrm{I} .05(0.4 \mathrm{I}-2.70)$ & 0.92 \\
\hline Female & $36(67.9)$ & $17(32.1)$ & & & \\
\hline \multicolumn{6}{|l|}{ Age category } \\
\hline$\leq 6$ years & 51 (50.49) & $50(49.5 I)$ & 0.03 & $3.16(1.23-8.16)$ & 0.02 \\
\hline$>6$ years & $34(69.4)$ & $15(30.6)$ & & & \\
\hline \multicolumn{6}{|l|}{ Hematuria } \\
\hline Present & $20(32.8)$ & $41(67.2)$ & 0.00 & $6.74(2.53-17.96)$ & 0.00 \\
\hline Absence & $65(73)$ & $24(27)$ & & & \\
\hline \multicolumn{6}{|l|}{ Infection } \\
\hline Yes & $29(40.8)$ & $42(59.2)$ & 0.00 & $3.28(1.35-7.97)$ & 0.01 \\
\hline No & $56(70.8)$ & $23(29.2)$ & & & \\
\hline \multicolumn{6}{|l|}{ Acute renal failure } \\
\hline Yes & $6(30)$ & $14(70)$ & 0.01 & $6.09(1.61-23.10)$ & 0.01 \\
\hline No & $79(60.8)$ & $51(39.2)$ & & & \\
\hline \multicolumn{6}{|l|}{ Dosing Frequency } \\
\hline Once-daily & $20(72.4)$ & $8(27.6)$ & 0.085 & $1.13(0.36-3.52)$ & 0.84 \\
\hline Twice daily & $65(53.3)$ & $57(46.7)$ & & & \\
\hline \multicolumn{6}{|l|}{ Remission } \\
\hline$>2$ wks & $25(35.7)$ & $45(64.3)$ & 0.00 & $3.69(1.54-9.09)$ & 0.00 \\
\hline$\leq 2 w k s$ & $60(75)$ & $20(25)$ & & & \\
\hline \multicolumn{6}{|l|}{ Serum albumin (g/dl) } \\
\hline$<1.5$ & $3(2 \mid .4)$ & II (78.6) & 0.01 & $8.38(1.71-41.13)$ & 0.01 \\
\hline$>1.5$ & $82(60.3)$ & $54(39.7)$ & & & \\
\hline
\end{tabular}

Note: $*_{p}<0.05$ statistically significance.

Abbreviations: AOR, adjusted odds ratio; Cl, confidence interval; FR/SD, frequent relapsing/steroid dependent; NS, nephrotic syndrome; SS/IR, steriod sensitive and/or infrequent relapsing.

$52.3 \%$ by Anigilaje et $\mathrm{al}^{24}$ and $56.3 \%$ Hussain et $\mathrm{al}^{17}$ and $55 \%$ by Sinha and Bagga. ${ }^{26}$ This poor response leads to prolonged use of steroids that contributing to increased morbidity, complications, and decreased quality of life. ${ }^{26}$ The differences in prognosis may be associated with variation in the dose and frequency of steroid administration, the duration of treatment for the initial episode, and the histologic differences. The longer duration of steroid therapy is associated with a reduced relapse rate. ${ }^{21}$

The majority of patients $64.2 \%$ encountered steroidrelated adverse effects in this study, the common toxicities were increased blood glucose $18.2 \%$, elevated BP $17.9 \%$, and moon face $15.7 \%$. In contrast to our findings, a study in Russia by Batishcheva et al reported overweight or obese, reactive pancreatitis, leukemoid reactions, and liver damage in more than $50 \%$ of the participants. The same study also revealed steroid-related toxicities such as Cushing's syndrome (44\%), chronic gastroduodenitis (33\%), hyperglycemia (11\%), arterial hypertension $(6 \%)$, and infectious diseases $(6 \%) .{ }^{27}$ Having a relapsing course of NS is associated with prolonged steroid treatment leading to an increased risk of steroid-related adverse effects. ${ }^{21}$

Steroid-resistant NS is difficult to treat with $36-50 \%$ of the patients progress to end-stage renal disease. ${ }^{28,29}$ In this study, $5.7 \%$ of the patients were resistant to steroid therapy throughout the follow-up period. Our findings are lower than the findings of resistant NS in African studies; $26.1 \%$ in Nigeria, ${ }^{24} 38.1 \%$ in Ethiopia, ${ }^{23} 42.6 \%$ in South Africa, ${ }^{22}$ and an average of $25.3 \%$ in African children. ${ }^{30}$ It is also lower than $10-15 \%$ resistant NS reported in a review by Tullus et al. ${ }^{29}$ The possible explanation for a lower rate of steroid-resistant NS in our study may be the 
difference in age, ethnicity, histopathologic type, or the difference in the study design. Although the biopsy test was not done, most of our participants probably had MCNS as remission with steroid therapy is indicative. ${ }^{3}$

Our study revealed that the predictors for FR/SD NS with steroid therapy were younger age ( $\leq 6$ years) at initial diagnosis $(p=0.00)$, presence of hematuria $(p=0.00)$, infection $(p=0.01)$, acute renal failure $(p=0.01)$, serum albumin below $1.5 \mathrm{~g} / \mathrm{dl}(\mathrm{p}=0.01)$ at diagnosis and lack of remission within 2 weeks $(p=0.0)$ of therapy. Similarly, other studies found a younger age at diagnosis, ${ }^{23,25}$ presence of hematuria, ${ }^{16,17,31}$ time to remission with initial therapy, and duration of steroid therapy, ${ }^{16,17}$ presence of infection, ${ }^{31}$ hypoalbuminemia ${ }^{19}$ were independent predictors of relapse. The possible reasons for the variations may be differences in sociodemographics and clinical characteristics included participants and study methods employed.

\section{Strengths and Limitations of the Study}

This study included all childhood NS patients treated with steroids in both hospitals. The period of 8 years data included for review was long enough to associate the outcomes. However, this study suffers from shortcomings of the retrospective study type. Besides, this study is conducted in two hospitals located in the same city, hence could not be representative of the whole population of pediatric nephrotic syndrome in Ethiopia.

\section{Conclusion}

Most of the pediatric NS patients treated in ACSH and MGH have achieved remission with initial to steroid therapy. However, there was a higher relapse rate among pediatric NS patients who achieved remission. Besides, steroidrelated toxicities were higher among children with NS, the common adverse effects being hyperglycemia, elevated BP, and moon face. The independent factors predicting FR/SD NS were early age $(\leq 6)$ at diagnosis, low serum albumin, presence of infection, hematuria, and acute renal failure at initial diagnosis, and lack of remission within 2 weeks.

\section{Abbreviations}

ACSH, Ayder Comprehensive Specialized Hospital; AOR, adjusted odds ratio; BP, blood pressure; CI, confidence interval; FR/SD NS, frequentrelapsing and/or steroiddependent nephrotic syndrome; MCNS, minimal change nephrotic syndrome; MGH, Mekelle General Hospital;
NS, nephrotic syndrome; SD, standard deviation; uPCR, urine protein to creatinine ratio.

\section{Data Sharing Statement}

The dataset supporting the conclusions is available from the corresponding author upon request.

\section{Acknowledgments}

The authors gratefully acknowledge Addis Ababa University for funding this research, Mekelle University for sponsoring the first author, and ACSH and Mekelle General Hospital for allowing us to access the data for conducting this study.

\section{Author Contributions}

All authors made a significant contribution to the work reported in areas of the study design, execution, acquisition of data, analysis, and interpretation, took part in drafting, revising, or critically reviewing the article; gave final approval of the version to be published; have agreed on the journal to which the article has been submitted; and agree to be accountable for all aspects of the work.

\section{Funding}

This work was supported by Addis Ababa University.

\section{Disclosure}

The authors declare that they have no conflicts of interest.

\section{References}

1. KDIGO. Kdigo clinical practice guideline on glomerular diseases; 2020.

2. Noone DG, Iijima K, Parekh R. Idiopathic nephrotic syndrome in children. Lancet. 2018;(18):1-14. doi:10.1016/S0140-6736(18) 30536-1

3. Gipson DS, Massengill SF, Nagaraj S, Smoyer WE, Mahan JD. Management of childhood onset nephrotic syndrome. Pediatrics 2009;124(2):747-757. doi:10.1542/peds.2008-1559

4. Eddy AA, Symons JM. Nephrotic syndrome in childhood. Lancet. 2003;362(9384):629-639. doi:10.1016/S0140-6736(03)14184-0

5. Chanchlani R, Parekh RS. Ethnic differences in childhood nephrotic syndrome. Front Pediatr. 2016;4(April):2-7. doi:10.3389/ fped.2016.00039

6. Downie ML, Gallibois C, Parekh RS, et al. Nephrotic syndrome in infants and children: pathophysiology and management. Paediatr Int Child Health. 2017:1-11. doi:10.1080/20469047.2017.1374003.

7. Uwaezuoke SN. Steroid-sensitive nephrotic syndrome in children: triggers of relapse and evolving hypotheses on pathogenesis. Ital J Pediatr. 2015;41(19):19. doi:10.1186/s13052-015-0123-9

8. Bagga A, Ali U, Banerjee S, et al. Management of steroid sensitive nephrotic syndrome: revised guidelines. Indian Pediatr. 2008;45 (3):203-214 
9. Mishra K, Kanwal SK, Sajjan SV, Bhaskar V, Rath B. Predictors of poor outcome in children with steroid sensitive nephrotic syndrome. Nefrologia. 2018;8(4):414-418.

10. Schijvens AM, Dorresteijn EM, Roeleveld N, et al. REducing STEroids in relapsing nephrotic syndrome: the RESTERN study protocol of a national, double- non-inferiority intervention study. BMJ Open. 2017;7(9):e018148. doi:10.1136/bmjopen-2017-018148

11. Park SJ, Shin J Il. Complications of nephrotic syndrome. Korean J Pediatr. 2011;54(8):322-328. doi:10.3345/kjp.2011.54.8.322

12. Asinobi AO, Ademola AD, Ogunkunle OO. Steroid response in primary childhood nephrotic syndrome in a tropical African environment. Niger J Clin Pr. 2019;22(6):790-795.

13. Nandlal L, Naicker T, Bhimma R. Nephrotic syndrome in South African children: changing perspectives. Kidney Int Rep. 2019;4 (4):522-534. doi:10.1016/j.ekir.2019.01.019

14. Doe JY, Funk M, Mengel M, Doehring E, Ehrich JHH. Nephrotic syndrome in African children: lack of evidence for ' tropical nephrotic syndrome '? Nephrol Dial Transpl. 2006;21(3):672-676. doi:10.1093/ndt/gfi297

15. Esezobor CI, Solarin AU, Gbadegesin R. Changing epidemiology of nephrotic syndrome in Nigerian children: a cross- sectional study. PLoS One. 2020;15(9):1-11. doi:10.1371/journal.pone.0239300

16. Carter SA, Mistry S, Fitzpatrick J, et al. Prediction of short- and long-term outcomes in childhood nephrotic syndrome. Kidney Int Rep. 2020;5(4):426-434. doi:10.1016/j.ekir.2019.12.015

17. Hussain AS, Abdulkareem AM, Hindi AN. The predictive factors for relapses in children with steroid-sensitive nephrotic syndrome. Saudi J Kidney Dis Transpl. 2016;27(1):67-72. doi:10.4103/13192442.174075

18. Mola K, Shimelis D. Pattern and outcome of renal diseases in hospitalized children in Tikur Anbessa specialized teaching hospital, Addis Ababa, Ethiopia. Ethiop Med J. 2016;54(3):117-123.

19. Gebrehiwot M, Kassa M, Gebrehiwot H, Sibhat M. Time to relapse and its predictors among children with nephrotic syndrome in comprehensive specialized Hospitals, Tigray, Ethiopia 2019. Int J Pediatr. 2020;2020:1-8. doi:10.1155/2020/8818953

20. Abeyagunawardena AS. Treatment of steroid sensitive nephrotic syndrome. Indian J Pediatr. 2005;72(9):763-769. doi:10.1007/ BF02734149
21. Hodson EM, Knight JF, Willis NS, Craig JC. Corticosteroid therapy in nephrotic syndrome: a meta-analysis of randomised controlled trials. Arch Dis Child. 2000;83(1):45-51. doi:10.1136/adc.83.1.45

22. Bakhiet YM, Mudi A, Khumalo T. Idiopathic nephrotic syndrome in South African children. Afri Heal Sci. 2017;17(4):14-16.

23. Imbusi EA, Ekanem PE, Gebrearegay $\mathrm{H}$, et al. Steroid response pattern among children with nephrotic syndrome in Northern Ethiopia. Nephro Urol Mon. 2020;12(4):e106995. doi:10.5812/ numonthly. 106995

24. Anigilaje EA, Fashie AP, Ochi C. Childhood nephrotic syndrome at the University of Abuja Teaching Hospital, Abuja, Nigeria: a preliminary report supports high steroid responsiveness. Sudan J Paediatr. 2019;19(2):126-139. doi:10.24911/SJP.106-1547399573

25. Ali EMA, Elhadi NM, Abdelraheem MB. Childhood steroid-sensitive nephrotic syndrome: characteristics and predictors of relapses (A Study at a Single Center in Khartoum). Sudan J Med Sci. 2018;13 (3):133-143. doi:10.18502/sjms.v13i3.2952

26. Sinha A, Bagga A. Nephrotic Syndrome. Indian j Pediatr. 2012;79 (8):1045-1055. doi:10.1007/s12098-012-0776-y

27. Batishcheva GA, Zhdanova OA, Nastausheva TL, Chernov YN. Characteristics of adverse side effects of corticosteroid therapy in children with nephrotic syndrome and methods of pharmacological correction. Res Results Pharmacol. 2019;5(1):37-43. doi:10.3897/ rrpharmacology.5.33831

28. Nourbakhsh N, Mak RH. Steroid-resistant nephrotic syndrome: past and current perspectives. Pediatr Heal Med Ther. 2017;8:29-37.

29. Tullus K, Webb H, Bagga A. Management of steroid-resistant nephrotic syndrome in children and adolescents. Lancet Child Adolesc Heal. 2018;4642(18). doi:10.1016/S2352-4642(18)30283-9

30. Olowu WA, Ademola A, Ajite AB, Saad YM. Childhood nephrotic syndrome in tropical Africa: then and now. Paediatr Int Child Health. 2017;9047:1-10. doi:10.1080/20469047.2017.1374002

31. Noer MS. Predictors of relapse in steroid-sensitive nephrotic syndrome. Southeast Asian J Trop Med Public Heal. 2005;36 (5):2005.
The International Journal of Nephrology and Renovascular Disease is an international, peer-reviewed open-access journal focusing on the pathophysiology of the kidney and vascular supply. Epidemiology, screening, diagnosis, and treatment interventions are covered as well as basic science, biochemical and immunological studies. The manuscript management system is completely online and includes a very quick and fair peer-review system, which is all easy to use. Visit http://www.dovepress.com/testimonials.php to read real quotes from published authors. 